\title{
GERONTOLOGICAL RESEARCH IN CHINA: THE ROLE OF ANTHROPOLOGICAL INQUIRY
}

\begin{abstract}
One fifth of the world's elderly population lives in China. Until recently political restrictions have hindered the conduct of research particularly ethnography. This piece provides an overview of recent research findings by Western scholars and of ethnographic research in progress in the areas of demography, state policy, age stratification, family planning, residence patterns, inter-generational transfers, patrilineality, health, illness, long term care, social welfare, and mortuary ritual. It analyzes the potential contributions of ethnography in this area.
\end{abstract}

Key Words: China, research, elderly.

\section{INTRODUCTION $1,2,3$}

In a review of the policies of developing nations concerning the elderly Treas and Logue (1986) identify four categories which describe the way different countries appraise the role of the elderly. In these the aged: (1) are seen as a low priority in development; (2) are cast as the consumers of scarce resources and as such impediments to development; (3) are portrayed as possible resources in development, as a flexible source of reserve labor in marginal enterprises; and (4) are depicted as the victims of the process of modernization.

The People's Republic of China (hereafter China) is perhaps unique among lesser developed nations in its awareness that social policy decisions regarding the aged cannot be made in isolation from policy decisions concerning the rest of the population. People's decisions about the number of children they will have, the kind of investments they will make, and, in some cases, the kind of social relationships they enter into are linked to their perceptions of their security in old age (Cain, 1985; Davis-Friedmann, 1983; Sankar, 1981). Studying aging and the aged in China presents an opportunity for examining the elderly not only as a distinct group but also as an integral part of the social order, an integration and interdependence which is made explicit by current political, social, and economic policy. Further, within the Chinese system of bureaucratic allocation of jobs, chronological age itself, or better cohort, is a significant factor in determining people's experience and opportunity in life. Thus, the study of age inevitably raises questions concerning fundamental aspects of social life in modern China. And, of course, one studies old age in China for the compelling reason that it has one fifth of the world's elderly population (lkels, 1988).

Despite significant and serious arguments which attest to the need to study aging and the aged in China, the amount of research which has so far been 
completed is slim indeed. Much is currently underway and will be reviewed here as in-progress, yet the subject calls for far more attention than has so far been accorded it both in the West and in China. This paucity is in large part due to the considerable political restrictions which, until recently, have impeded all research, but especially ethnological and ethnographic investigation. Restrictions on Western scholarship, although more flexible, are still a force in discouraging the rapid expansion of this research area. They offer a partial explanation for the thinness of our current understanding of aging and the aged in China particularly in regards to the contribution of Western scholars. (For ethnographic studies conducted prior to the Cultural Revolution (1966) or in Taiwan or Hong Kong see for example: Baker, 1968; Cohen, 1976; Diamond, 1969; Fei, 1949; Freedman, 1958; 1966; Fried, 1953; Gallin, B. 1966; Gamble, 1954; Ho, 1962; Hsu, 1948; Ikels, 1983; Lang, 1946; Lin, 1948; Sankar, 1978; Tawny, 1932; Wolf, A. 1968; Wolf, M. 1972; Yang, C.K. 1959; Yang, M. 1945.)

A more pressing impediment to our appreciation of aging and the aged in China, and one which is likely to grow more weighty rather than shrink with time, is the considerable diversity wrought by ethnic, regional, and economic differences. One cannot talk about the Chinese elderly with any real precision except when demographically describing them. For example, there is the fact that until very recently the population planning policy of restricting couples to one child did not apply to non-Han ethnic groups. As economic policies which favor coastal regions over the interior are pursued, regional economic differences and their effects on the well being of the elderly are likely to intensify.

This review has three main objects; 1) it will identify the kind of research which has been done; 2) it will synthesize what is currently known about the elderly and age in China with particular attention to those areas directly affected by governmental policy; 3) it will review research currently in progress and suggest areas which might be addressed in future work. It will take as its main focus the effect of state policy on the experience of age. In part this is an obvious orientation given the extreme social change which the Chinese Communist Party has fostered since coming to power in 1949. It also reflects the simple fact that until recently Western researchers had more access to policy pronouncements than to the actual situation and thus focused their research questions on issues related to state policy.

Despite the limits on our understanding of old age imposed by both the nature of the object of study and by the political context in which the study must take place, this is a particularly compelling subject; for it allows us to critically examine the almost mythical Chinese gerontocracy standing as it does for a "golden age" when families "really" took care of the elderly. This myth informs the policy ideals of Western governments and its critical examination is long overdue. 


\section{SOURCES AND METHODS}

To date there has been relatively little ethnographic work focused specifically on aging and the aged in China, although some projects of this nature are currently underway and will be discussed in a later section of this paper. The ethnographic data presented here come from three sources. The initial results from Charlotte Ikels' work (1988, n.p.) represent direct ethnographic data on Chinese elderly. Other data presented here are culled from ethnographic accounts which were not directly focused on the elderly but on related subjects such as life history or the family (Huang, forthcoming; Dong, 1987; Davis, n.p.).

To provide the reader with the background necessary to fully appreciate the salient issues in Chinese gerontology, I have had to draw extensively on material which ranges from interviews (Davis-Friedmann, 1983, 1985b; Davis, 1986; Greenhalgh, 1986; Ikels, 1983, 1988, n.p.; Whyte, 1988), to a combination of interviews and participant observation (Croll, 1987; Davis. n.p.; Dong, 1987; Huang, forthcoming; Nee, 1985, 1986; Wolf, 1986) to survey research in China (Amold, Zhao, 1986; Gui et al., 1987; Liu and Yu, 1988; Yu et al., forthcoming), and analytic pieces based on secondary sources (Davis-Friedmann, 1985a; Keyfitz, 1984; Liang, Tu, Chen, 1985; Liang and Gu, n.p.; Olsen, 1987, 1988).

Before reviewing this material, it is important to again emphasize its inherent limitations. China is a large country with distinct ethnic and regional divisions. Even the results of a random sample of 1000 respondents from an urban area must be viewed with caution because the results represent, at best, the conditions of that urban district, or perhaps of only one area of that district in a city such as Shanghai. In some respects the qualitative data provide a more accurate picture because the reader can clearly appreciate the nature of the study population and hence its limits. The portrait which follows will be painted with broad descriptive strokes. It should, if successful, raise more questions than it answers.

\section{THE EXPERIENCE OF AGE IN CHINA}

\section{The Impact of State Policy}

Since the 1949 Revolution, the Chinese Communist Party has attempted to institute social changes which extend far beyond those tied to the means of production. The most significant policies in this regard are those pertaining to population control, or the lack of it, and to the distribution of jobs. The ramifications of these policies have had a profound impact on people's experience of age.

Demography. According to the 1982 census there were 49 million people 65 and older in China. Although the age of 65 is used in the United States for the purposes of long range planning, in China the general retirement age is 60 for 
men and 50 or 55 for women depending on the type of job they held so that the number of those 60 and over will be cited as the relevant statistic because it is the one on which the Chinese base their planning. In the 1982 census there were 76.6 million people sixty and over who constituted $7.6 \%$ of the population (Liang, Tu, Chen, 1985). According to this census, the life expectancy for women born in 1981 was 69.4 years and for men 66.4 years. Given the decline in birth rate and the steady mortality rate, the population is expected to age rapidly especially if the one-child fertility policy, which is designed to reduce the population size, is successful. Projections concerning the future growth of the elderly population vary somewhat according to different forecasters. The above authors suggest that there will be a relatively favorable dependency ratio until the late 2020's when the large birth cohorts of the period 1960-1975 begin to retire (ibid). At this point the proportion of elderly in the population will begin to increase rapidly, reaching $20 \%$ by 2040 . Other researchers estimate that a crisis will be reached as early as 2000 (Bannister, 1987) or 2005 (Keyfitz, 1984).

These figures are slightly misleading because the population will age at different rates depending on its geographic location and urban/rural mix. In Shanghai the 60 and older population already accounts for $11 \%$ of the population. This figure rises to $13 \%$ if the suburban regions are included (China News Analysis, 1984). It is projected that by the year 2000 the figures will be $18 \%$ for the urban area and $20 \%$ for the urban and suburban areas combined (ibid). Combining urban and suburban areas does not always result in an increased ratio. In Tianjin those 60 and older currently account for $8.7 \%$ of the population, a figure which drops to $7.97 \%$ when combined with the suburban population. This brief comparison serves as a reminder of the dangers of making global statements when one is describing the elderly population in China.

Demographers speculate that some kind of crisis will develop in the first half of the twenty-first century brought on by the movement of the huge birth cohort from the 1960-75 period into retirement and the introduction of a strict population planning program which aims to develop negative population growth through the one child family campaign. If this campaign is completely successful, Bannister (1987) predicts that the elderly will constitute $41-45 \%$ of the population by the middle of the next century. Liang et al. (1985) estimate that by 2042 the dependency ratio will be 34 elderly for every 100 workers. The government and the research institutes which sponsor research by Westerners will expect that much of the research on aging carried out in China during the coming years will address this phenomenon in some fashion (Greenhalgh, 1988).

Age Stratification. Government policy has had a powerful and pervasive impact on the experience of age through bureaucratic allocation of jobs which guarantees strikingly different opportunities and rewards for individuals depending on the cohort into which they were born. In this respect, argues Davis-Friedmann (1985a), China is similar to other contemporary state socialist 
systems. She describes how a system of age stratification has developed whereby "first-comers", those entering the workforce during a period of economic expansion, are systematically given advantages over "late-comers", those who arrive on the job market during a time of economic contraction. Because of consistently high birth rates and uneven rates of job creation, the time at which one entered the work force determines one's access to a vastly different set of opportunities and rewards in life. Thus, a system of generational cleavages has evolved whereby many newly retired people have a higher income than their middle aged children.

Davis (1988) attributes the development of this system of job allocation to the strength of an entrenched bureaucracy, to the control of the military over the bureaucracy for many years (i.e. in the military the needs of the labor force for personal fulfillment and advancement need not be attended to), and to the manipulations of the political leadership in its move towards transforming the economy. Since the revolution class inequalities have decreased only to be replaced by inequalities based on age, gender, region, and economic sector. These inequalities are likely to increase as the government moves towards contract labor as the officially sanctioned mode for recruiting new labor. This allows managers to have more flexibility in managing their workforce by doing away with the "iron rice bowl", the job for life system. Contract workers, however, have a distinctly reduced system of rewards and opportunities than permanent workers, those hired before 1986 when the system of contract labor took effect (ibid). The potential antagonisms between the generations which this could create worries many political planners and was noted repeatedly in the works by Chinese scholars in the Gerontological Society of America's special publication, Aging China: Family, Economics, and Government Policies in Transition (1987).

The One-Child Campaign. Perhaps the relationship between the welfare of the elderly and the family planning activity of the young has never before been so explicitly recognized as by those government planners trying to make the onechild campaign a success. A common bleak image used to criticize the campaign's goals is that of a middle aged couple responsible for the care of four elderly parents and one teenager. To disarm this fear and alter the socioeconomic factors which lead to high fertility, family planning programs have begun to emphasize the need of the government to "render service" (Greenhalgh, 1986). Cadres, the professional political workers and members of the Communist party, have become involved in helping couples solve problems ranging from old age support to gaining access to labor and capital. Davis (1986) argues that the specter of the overwhelmed middle aged couple is inaccurate. She points out that in the near future, with the movement of the baby-boom generation through the workforce, dependency ratios will drop. This will produce more spendable income. A whole range of social shifts may result. More income could reduce the need to share housing, although the number of available units remains a problem. It could also allow the middle aged to hire 
help to care for the elderly. She speculates that the reduction in the necessity for intergenerational interdependence will produce new forms of family relationships, similar to those that exist in Western industrialized countries, which demonstrate the full spectrum from great interdependence to complete independence (1986).

Aware of the problems the one-child policy will create for the family in its ability to care for the elderly, the Chinese government has already begun to modify the campaign. In rural areas numerous exemptions, including those designed to acknowledge patriarchal traditions, have been introduced. In effect, these allow for most families to have two children. In urban areas, however, the fertility rate is between 1.0-1.4 births per woman which will cause severe population aging unless fertility increases or there is significant in-migration (Bannister, 1987). Several solutions involving birth spacing are being considered to ameliorate the problem of urban aging. One possible solution would be to adopt a policy which allows a couple to have one child soon after marriage and a second four to six years later (Greenhalgh and Bongaarts, 1987). The onechild campaign poses a significant challenge to the government to provide for the pension and medical coverage for workers after the low fertility rate has weakened the family structure on which they now depend (Bannister, 1987).

\section{Social Change and the Elderly}

Beyond specific governmental policies, the state has affected the experience of age through the wider social transformation which it has fostered. The impact here is seen in such areas as indirect influence of housing availability on family residence patterns, efforts to discourage son preference, and the kinds of reciprocal relationships between generations which urban living and the employment situation necessitate.

Co-residence. Chinese elderly continue to residue with at least one child in significant numbers. Davis-Friedmann (1983) in a study undertaken in the 1970 's estimated that at that time $70 \%$ of rural elderly and $90 \%$ of urban elderly lived with at least one child. These figures have changed slightly according to a more recent study which draws on the 1982 census. Gui et al. (1987) report that in Shanghai three out of four elderly live with at least one child. In the most recent available results, Liu and Yu (1988) report, based on a random sample of 5050 people 55 and older living in Shanghai, that $73 \%$ of the sample live with at least one child and only $6 \%$ live alone. Although co-residence reflects the cultural ideal of the extended family living under one roof, more practical factors may promote the prevalence of this pattern. The high rate of coresidence, especially in urban areas, may in part be due to a severe housing shortage. Davis (1986) suggests this when she compares the higher co-residence rate in Shanghai, with its extreme housing shortage, to the lower rates of both Beijing and Tianjin, which have recently increased their housing stocks.

In urban areas joint living also may be related to household wealth (Davis, 
1986). Davis's 1986 research in Shanghai indicated a curvilinear relationship between household wealth and family size. The wealthier and the poorer families included three generations while those in the middle had one or two. Only the wealthiest, usually veteran cadres, have generous living quarters and the poorest simply jerrybuild extra spaces onto their living quarters to accommodate married children (ibid).

In her ethnographic and interview study of the families of researchers at the Chinese Academy of Sciences in Shanghai, Dong (1987) substantiates Davis's analysis, at least for the wealthiest group. The difference in living space allocated to the older, established scholars and the middle aged and younger researchers was dramatic. As researchers progressed in seniority and authority within the Academy, they were given more living space in accord with their rank. Thus, senior researchers with grown children not residing at home might have a four room apartment with up to 92 square meters of living space. On occasion this space had to be shared with other families which the work unit would temporarily house there. But this spacious allocation was the norm for the senior researchers and their spouses. In 1980 the average Beijing resident had 4.79 square meters ( 52 square feet) of floor space in which to live. Among the junior researchers at the Academic Sinica, it was not unusual for a couple and their one child to live in 12 square meters. When a couple did not have sufficient living space, one or more children were sent to grandparents to live until the family obtained adequate housing. With such significant disparities in living conditions it is not surprising that many young couples ended up living with one set of parents.

Research results are not consistent in reporting the preferences of the elderly concerning co-residence. According to Yuan (1987) the shift toward more independent residence in Beijing corresponds with the desires of the elderly. In reporting results of a survey from Beijing, he states that $100 \%$ of the elderly interviewed who were living alone wanted to continue to do so and $23.5 \%$ of those who were currently living jointly would prefer to live only with a spouse. In the rural areas the situation seems somewhat reversed. Results from a survey of rural areas of Heilongjiang and Sichuan showed that $40 \%$ of the elderly reported that living jointly was the ideal but that only $27.9 \%$ actually did so (ibid). In a survey of elderly Shanghai residents Gui et al. (1987) found that $32.7 \%$ preferred to live only with a spouse and with a child nearby. Significantly, they report that the percentage of those preferring to live alone declined with age. A 1986 study conducted in Hubei, which does not indicate its urban/rural mix, found that $48 \%$ of those elderly living with their children cited dependency as the reason, 23\% identified helping with the chores, $15 \%$ responded enjoyment of family life, and only $14 \%$ gave as the reason, housing shortage (Liang and Gui, n.p.). Because of the dependence of many elderly, especially those seventy-five and above, on their family for support and because of the severe housing shortage in most urban areas, it is difficult to clearly establish their preference for living arrangements when alternatives to their present situation are non-existent. 
Pasternak (1986) reaffirms the difficulty of imputing values or attitudes about co-residence from housing patterns. In a study on demographic trends conducted in two neighborhoods in Tianjin from 1981-82, Pasternak reports that neolocal residence has been increasing since before 1949. Migrants coming to the city accounted for the early trend. Except for times of economic or political reversal, the trend has continued. Since 1969 shortages in housing stock have put a minor restraint on neolocality. Not only are housing units in short supply but the space within a unit is extremely limited forcing young married couples to leave their parent's quarters as soon as possible. According to Pasternak's informants this is not always desirable. They cite a preference for living with parents in part because of the help provided by the mother-in-law for child care and household management. Older people, however, appear to be less enthusiastic about residing with their children. Pasternak reports that a 1985 survey of 1000 households showed a $10.1 \%$ decline between 1983-85 in those desiring to live with their children to only 50\% ("China Daily News", 2 January 1986:4 in Pasternak: 34). Despite this stated preference only $4 \%$ of his informants lived alone; $49 \%$ lived in nuclear households and $45 \%$ were members of extended households. Clearly more work needs to be done to disentangle the effects of the housing shortage from residence preference.

Patrilineality. Sons and daughters equally are required by law to support their elderly parents. But the cultural expectation that one son will assume the care of aging parents remains strong. When parents do reside with their grown children, there is a clear preference for residing with a married son. In Gui et al.'s study of Shanghai (1987) they found that among those elderly who preferred living with a child as opposed to living alone with a spouse, $26.9 \%$ preferred living with a married son, $18.1 \%$ had no preference and $12.4 \%$ preferred living with a married daughter. Davis (1986) found fewer than $10 \%$ of her older informants living with newly married daughters; in contrast, $40 \%$ of the newly married sons continued to reside at home.

The continued strength of son preference has become strikingly clear with the introduction of the one-child campaign. Despite the government propaganda which features a girl child as the one child, there remains a strong preference for sons, so much so that the practice of female infanticide again appeared after the initiation of the campaign (Nee, 1986). As the political pressure for gender equality waned with the move toward decollectivization, the authorities were unable to discourage the expression of the preference for sons, especially in its extreme form, female infanticide (ibid). The one-child campaign in rural areas has been modified to acknowledge the patrilineal tradition by allowing families to have a second child if the first is a girl (Greenhalgh, 1986). In this way, if both children are girls, one daughter can be married out and an uxorilocal husband can be married in to care for the parents in old age.

Davis-Friedmann (1985b) suggests several economic and structural reasons for the continued preference for sons in rural areas. Unlike urban areas where children are often seen as long term dependents, in rural areas elderly parents 
rely on their children for support in old age. She attributes this to three factors: (1) because women do not earn as much as men, a disadvantage which is compounded by the unpaid housework which they must perform, they cannot provide as well for their parents, (2) although the government has tried to discourage surname exogamy, the continued strength of this practice makes it difficult to maintain close ties with married daughters, (3) the practice of ancestor worship in which the son must officiate in the rites for the deceased parents creates a religious preference for sons.

In an impressive example of ethnographic work, Davis (n.p.) explores the significance of domestic interiors and of popular culture in Shanghai. Based on a sample of one hundred families containing a woman born between 1925 and 1935, she argues that the concept of the "mother's house" serves as a strong emotional anchor for urban informants. She analyzes photographs in the homes she visited and argues that matrilineal ties are very strong despite the pattern of patrilocal residence. "Home is the home of the mother," she concludes. The interiors of her informants' homes, despite their patrilocality, clearly reflect the strength of the tie to the mother and the primacy of women in the domestic sphere. To some extent this is what one would expect in a strongly patrilinear society; nonetheless, this finding, if born out in large data sets, may indicate the kinds of caregiving relationships to which older women might have access.

Reciprocity. Relationships within the Chinese family have traditionally been marked by strong intergenerational support and reciprocity. Children care for their parents in old age in return for their care when young and for the gift of life. Few families have the surplus wealth to allow the elderly to "retire" within the family. Even in extreme old age the elderly are expected to contribute to the household economy whenever possible.

The way such support is actualized differs markedly in rural and in urban areas. In rural areas where $75 \%$ of the working population lives, the elderly have been cared for by their sons, who consider it a joint responsibility. At the time of household division, either one son is given a larger share of the patrimony with which to provide the aging parents with care, or the sons divide up the support for the parents more or less equally. In some cases different children care for the father and for the mother.

In the 1950 's, $60^{\prime} \mathrm{s}, 70^{\prime} \mathrm{s}$, and even into the early $80^{\prime} \mathrm{s}$ agricultural production was collectivized. Neighbors worked in work teams; teams were formed into brigades (which were usually synonymous with the former village); and brigades were organized into communes. Workers were assigned work points according to age, gender, and the amount they worked, not what they produced. At the end of each year the work points were totaled and people were paid in food stuffs and cash according to the number of points they had accumulated. The elderly who had retired from the workforce were still able to contribute to the family income. They were not obligated to work a set number of days on the collective and could instead concentrate their efforts in the private sector and contribute to their own subsistence and sometimes to the household economy. 
Davis-Friedmann (1983) illustrates in detail how the raising of a pig to be sold on the private market by the grandmother could generate substantial income for a family.

The potential economic contribution of the elderly has increased under certain circumstances since decollectivization and the revival of traditional family production units. In rural areas it was often the "young old" men in their fifties who initially benefited from the introduction of the new responsibility system (Davis-Friedmann, 1985a). They had the developed social networks, skills in traditional handicrafts, marketing savvy, and often the ownership of traditional means of production such as specialized artisan tools. Even a much older person who is skilled in handicrafts or can free up the labor of adult family members by attending to household chores can aid the family in advancing economically in the now tightly competitive atmosphere of rural production where even marginally useful labor can give a family a competitive advantage.

The rural elderly without sons to care for them, those eligible for the "Five Guarantee" program have not fared as well under the new responsibility system. Without the social and political pressure to contribute to the social welfare fund, these funds are dwindling and more and more elderly without sons must care for themselves and face a significant decrease in standard of living. In Huang's (forthcoming) account of village life, the chief protagonist, P.S. Yie, first secretary of his brigade (a position roughly equivalent to a mayor), expressed serious concern for the effect of decollectivization on the poor and elderly. A decrease in the standard of living for the dependent elderly, those in five guarantee households, has also been reported by Greenhalgh (1986). The new responsibility system may also be affecting the well being of elderly within their own families. In Davis's (1986) analysis she reports that the new responsibility system has reduced the pressure on children to support elderly parents who can no longer make an economic contribution to the household. For example, Western researchers' reports show that between $10-20 \%$ of the elderly in some Guangdong villages are not living jointly with their children but must instead "go it alone."

The situation for the urban elderly is strikingly different. Due to a wage system which until recently has been strictly tied to seniority, senior workers by definition earned more than younger workers. For example, in Dong's study (1987) an average working couple at the Chinese Academy of Sciences in their 40 's earned a combined income of 156 Yuan (approximately US\$ 78) a month, a couple in thier 50's earned 231 Yuan a month, and a couple in their 60's 332 Yuan a month. (These figures do not reflect inkind subsidies provided by the work unit.) In 1978 the government decided to change the pension system in the state sector to increase access to jobs for younger workers. Since 1978 the government has pushed for the mandatory retirement of women over 50 in manual labor, over the age of 55 in white collar labor and for men over 60 which has resulted in a phenomenal growth in the number of pensioners (Davis, 1988). Currently, pensions provide for $70 \%$ of the last wage. This generous retirement benefit has made these "young old" a significant economic force in their 
families.

The economic advantage for the newly retired has, in some cases, been compounded by those who choose to go into part-time or entrepreneurial activities. Participation in entrepreneurial activities appears to depend on the adequacy of retirement income. Liu and Yu (1988) report from their Shanghai study that less than $10 \%$ of those retired work full time and only $1.2 \%$ work part-time. Of those retired, 88\% did not want to work. Liu and Yu (1988) point out, however, the significant income differential between those fifty-five and older who are retired and those who are still working. The mean income for those working was $69.2 \mathrm{RMB}$ and the median $67.00 \mathrm{RMB}$ compared to a mean income of $99.8 \mathrm{RMB}$ and a median for $93.00 \mathrm{RMB}$ for the retirees. The relative affluence of some elderly has not affected those elderly who did not work in state enterprises and therefore were not covered by a pension. They must still rely on their families and paid labor for most of their support.

As in rural areas, urban children are responsible for the care of their elderly parents. In most cases urban adult children continue to make regular contributions to their parents' income. With a combination of a high retirement income and possibly an ample apartment allocation, the urban young-old can be a potent force in their adult children's lives (Davis-Friedmann, 1983) in some cases supplying support in the form of regular payments, free meals, or loans (Dong, 1987). Liu and Yu (1988) report that elderly informants provided material support to their adult children from their pensions and that they received help in health care provision from the children. This also, as Dong points out, can lead to a reassertion of tyrannical patriarchal control over the lives of adult children.

The reciprocal relationship between the urban elderly and their adult children takes many forms. One of the most important roles which the elderly play is the provision of child care for grandchildren. Liu and Yu (1988) report that 50\% of the respondents had grandchildren living with them and that $68 \%$ said they helped in child care. The extent of this care is not specified. Usually grandmothers play this role but grandfathers are on occasion the providers. Most adult women in urban areas work full time. The state childcare facilities will not take children under the age of two, and are said to be no where near adequate to meet the demand (Dong, 1987). Some few work units provide on-site care for infants but these are rare and usually full. Grandparents, when available, are very important in the care of infants and young children. The grandparents may care for the child in the parents' living quarters, or the child may be sent to live with the grandparents, either the father's or mother's parents, until he or she can enter a day care center at age two or until school begins at age seven. In Dong's study the parents usually pay the grandparents for this care. The amounts reported by Dong were equal to or greater than non-kin child care (ibid). This is not always a satisfactory arrangement for either party. Parents would rather have the children with them; they worry that the grandparents are spoiling the children. The grandparents find the task sometimes overwhelming. An additional problem is related to task appropriateness. Dong reports that the newly retired, educated grandmothers are sometimes not willing to adopt the role of 
babysitter. In one informant's family, the grandmother contributed to the salary of a governess to free herself from what she saw as inappropriate work. In this changing environment the new young-old can not be seen as an assured source of child care.

Elderly parents can also provide valuable assistance in household chores. With both members of a couple working full time six days a week, housework is extremely difficult to accomplish. This is compounded by a scarcity of modern appliances and in some cases even running water is lacking (Dong, 1987). Household work also includes standing in long lines to shop, a daily task in the many households that lacked refrigeration. The nature of these difficulties is changing as more labor-saving appliances become available. Labor-saving appliances are not widely distributed, however, and the presence of a grandmother in the household is still considered to give a family a clear economic advantage (ibid).

One of the most significant kinds of transfer from the older generation to the younger one was the practice of ding-ti. After the Cultural Revolution, young adults who had gone to the countryside to work with the peasants and to spread revolution, the "sent down youth", returned to the cities seeking work. To accommodate these youths and to ensure that they did not create social unrest, the government modified an established but highly restricted system of job transfer called ding-ti, whereby a parent, upon retirement, could pass his or her place in the work unit to a designated child. The modifications allowed any parent to exercise this option. In its first year of operation (1978-9) the retirement rate doubled (Davis, 1988). The number of retirees increased 400 per cent between 1978 and 1985 (ibid). This benefit is being phased out because of the management problems it created although it continues to exist informally (Dong, 1987).

\section{Health, Illness and Care}

There is little systematic epidemiological data describing the health and functional status of the Chinese elderly. Studies to assess this population are underway as are studies to determine how long term care is provided both within the family and from the outside. The data presented here represent, with the exception of the Alzheimer's study, snapshots of the situation. Considerably more data is needed.

Health. The government has established some policies which are aimed at enhancing the quality of life of the elderly thus indirectly reducing their burden on the family by improving health and well being. National magazines written specifically for the elderly and several minor publications and political pronouncements aimed at the elderly urge them to remain physically and socially active. Numerous educational programs are available to retired workers (Hu et al. 1987). In some urban areas, residents committees have set up a kind of senior center (lao ren zhi jia) where they read, meet, and play games (Olsen, 
1988). Urban elderly are encouraged to volunteer their services on behalf of political and social causes (ibid).

IIIness. Yu et al. (forthcoming) have conducted the first longitudinal study of Alzheimer's Disease and dementia in China. They tested a probability sample of 5,055 non-institutionalized elderly 55 and older in Shanghai with the Chinese version of the Mini-Mental Status Examination (CMMSE) which they developed. In their initial findings the most remarkable results are the relative well being of the sample and the gender differences in illiteracy and cognitive impairment. Overall $4.1 \%$ of those 55 and older may be classified as having severe cognitive impairment while they found $14.4 \%$ with mild impairment. The rates for women were consistently higher than for males by a ratio of 3.75 in the severe group and 2.6 in the mild group within each age group. The cognitive impairment rates vary by education within each age group. When sex is controlled for, educational attainment had a highly significant inverse relationship with the prevalence of cognitive impairment. When education was controlled for, sex was significantly associated with the prevalence of cognitive impairment. Their findings suggest that basic educational deficits can have a significant impact on human cognitive functioning.

There is the important but relatively untouched area of the elderly's perception of health and illness. In a tangential way, Kleinman's study of culture, health and illness in Taiwan (1980), pointed out that the elderly in many cases have a complex, traditional understanding of the relationship between old age and disease. Sankar (1984) described how this conceptual relationship affects both the decision to seek medical care and the care which is expected and accepted. In a study of two neighborhoods in Guangzhou, Ikels (1988) includes in the reporting of her results observations which are relevant to this topic although not of central concern to the research. Ikels suggests that disability rates reported by her elderly informants are lower than they might otherwise be given the extent of physical impairment because of co-residence and family organization. That is, by continuing to live within the family the elderly may not need as high a level of functional ability to remain active as someone who resides alone which is the preferred residence pattern in the West. This is an extremely interesting suggestion and one which needs more systematic investigation.

Without attempting to adequately discuss the field, I will mention four of the more prominent works by Chinese authors in the area of health and wcll being. In a review of the chronic health problems of the old Laonin Baojian Zhishi (Information for Preserving the Health of the Old) (1978) Xia Lianbo describes the different problems which can be helped by diet and exercise. This popular book is one of the first to define old age as a social problem.

A volume edited by Yuan Jihui called Laonian Wenti (Problems of Old Age) (1986) includes essays based on recent fieldwork on such topics as elder suicide, remarriage, economic status, care of the childless, recreation centers, psychiatric needs. Its appendix lists key recent publications on issues concerning the 
elderly. Yuan Jihui has also edited the two volume Laonian Shenghuo Yanjiu (Research on Urban Elderly) (1986). The first volume reviews the 1982 census and the 1983 survey of elderly in Shanghai with special attention to health status, family relations, and economic resources. The second one further discusses the 1983 survey and provides more information which compares rural and urban elderly in the Shanghai area.

Single and Childless Elderly. Studying the lot of single and childless elderly provides a revealing perspective on the formal and informal provision of social welfare in a society. In pre-revolutionary China there were a myriad of cultural forms to allow for the provision of care to elderly without children. In a study of the remaining members of an anti-marriage movement in Guangdong, Sankar (1978; 1981) documented numerous forms of social relations which enabled childless elderly to be cared for in old age. These included the creation of fictive kin relationships which established ties of mutual obligation, formation of communal associations among childless elderly, the adoption of a relative's child, care by the lineage, entrance into the religious life, and contracts which arranged for one man's wife to be "rented" for a specific time period by another man for the purposes of bearing children who would then belong to the lessor and his wife. Davis-Friedmann (1983) recounts the strategy of childless rural elderly, male and female, in post-revolutionary China who create strong reciprocal bonds of mutual obligation with younger neighbors, usually "sent down" urban youth, in return for care in old age. These bonds were necessary despite the assistance provided by the Five Guarantee program which was administered unevenly and provided only minimal help in housing, clothing, medical care, education and funeral expenses.

Since decollectivization these childless elderly are some of those at greatest risk. In 1986 there were 347,979 needy childless elderly in urban areas and in rural areas there were 2.4 million Five Guarantee households of childless or single elderly (Liang and $\mathrm{Gu}, \mathrm{n} . \mathrm{p}$.). In explaining this reduction in care Nee (1985) speculates that one of the reasons that collectivization did not work was because of the fear of "free-riders", those who did not contribute their fair share to the collective effort but who were entitled to an equal share of the profit. He suggests that the negative experience with "free-riders" under collectivization has eroded a sense of community charity leaving those who used to be assisted by the Five Guarantees, which included the childless elderly, more vulnerable to economic reversals than they were in the past.

This problem is by no means being ignored by the government. If childless elderly meet the qualifications of the 3 No's - no children, no capability to work, and no other means of support - they will be eligible for social welfare (Liang and $\mathrm{Gu}$, n.p.). The government has chosen to make the childless elderly the target of social welfare programs for two reasons, Ikels argues (1988): first, they are a small and limited number and therefore the cost of caring for them cannot get out of hand; second, adequately providing for needy elderly will help promote the one-child campaign. Government planners eager to make the one- 
child campaign a success realize that the specter of elderly, no matter what their family composition, who are clearly destitute will confirm people in their desire to have more children. In some areas the local cadres have increased the amount of assistance to the Five Guarantee elderly, assigned people to help them, and constructed old age homes furnished with modern conveniences. In other areas, worker-contributed pensions have been instituted for childless rural elderly (Greenhalgh, 1986).

Long Term Care. Liang and Gu (n.p.) estimate that at the present time there are some 12 million disabled elderly requiring assistance in daily life. Only .05\% of them are cared for in an institutional setting. It is difficult to conceive how this ability to care for the elderly outside of institutional settings will continue with the decrease in family size. Even if the one-child policy is modified to allow two children and the proportion of elderly only reaches $22 \%$ by the middle of next century, the numbers of the oldest old, those 80 and above will still continue to increase rapidly and will create an immense social burden (Bannister, 1987). It is further likely that the problems created by shifting demographics will be exacerbated as the new economic freedom increases employment choices for rural youths, attracting them away from the farm and away from the care of aging parents (Ikels, n.p.). Families are developing a variety of informal solutions to these problems, while the government is moving to address the issue both directly and indirectly. If the government were to relax its policies discouraging in-migration to the cities, this might alleviate the urban family's care burden by making hired help available (Bannister, 1987).

The concept of care for the elderly outside the boundaries and idioms of kinship is slowly emerging. For families that are separated and for others where both people in the couple work full time, private home care is becoming an option. In recent years there has been a rapid growth in the number of young women from rural areas who migrate to cities to work as maids (China News Analysis, 1987). These maids, sometimes called baomu (nursemaids), in many cases appear to serve the role of home health aide (Dong, 1987). They come to achieve independence from their families or to save money for a wedding. In some areas there are government initiated home care services (Fang, 1987). Their pay varies according to skill but can go as high as 200 yuan a month, which is comparable to the lower level researchers at the Chinese Academy of Sciences.

The government has developed a number of policy initiatives designed to indirectly support the family and alleviate the strain of caring for the elderly. The policy of assigning college graduates who are only children to a job near their parents is an example of this. Because university graduates must accept any job assignment given them at graduation, and because these job assignments need not be near their home town, young, highly qualified students are choosing a local college rather than a national university for their advanced training so as to ensure that they will remain near their parents. As a result, some university candidates seek education which is not commensurate with their skills according 
to Dong (1987). To avoid this and to promote the one-child family, the state is trying to settle only children near their parents and is giving the aim of reuniting a family high priority in approving job transfers (ibid). Yet the problem still remains.

In addition to the informal solutions to parent care, the government is moving towards the actual provision of care by building old age homes. These are still few in number. In 1984 there were 169,000 or $.33 \%$ of those over 65 in nursing homes (Liang, Tu, Chen, 1985). This represents 684 homes in urban areas caring for 22,000 people and 11,000 homes in rural areas caring for 147,000 people. The quality of these homes appears to some extent to be tied to the local family planning policy. In areas where this is a high priority the homes are appealing, representing a visible symbol of the state's attempts to reassure people about their care in old age (Greenhalgh, 1986). They are not nursing homes, however, but homes for the childless elderly capable of self care. Eventually they will take on more of the aspects of a nursing home as their inhabitants age. The government has set a goal of establishing at least one old people's home in each township (xiang) (Olsen, 1988).

The government is encouraging the development of pensions in the countryside. But the progress is slow. In 1980 only 180,000 or approximately $.4 \%$ of the rural elderly received pensions. By 1983 that number had grown to 600,000 with approximately 9,000 brigades providing some kind of pension (Liang, Tu, Chen, 1985). This issue of rural pensions is a significant one for China's future development. It is one, however, which will be extremely difficult to resolve given the potentially large numbers involved and the limited resources with which planners must work.

Direct services are available for childless urban elderly from the social welfare fund. The government also subsidizes the home services provided by home care teams to the most debilitated elderly who require complete care (Liang and $\mathrm{Gu}$, n.p.). Neighborhood clinics operate a Home Sickbed program for people unable to get to the clinic. Physicians attend to those recently discharged from the hospital, acute and emergency cases; and nurses visit the chronically ill (Ikels, 1988).

\section{Death}

Although death is not the special domain of the elderly, it is a topic which greatly concerns them and their families. Traditionally providing for an appropriate and proper funeral was one of the most important obligations which a child owed its parents. As parents aged both they and their children were aware of the need to provide an adequate funeral. In many cases the parent saved money to ensure the adequacy of the funeral. With its attempt to change mortuary ritual, the government has directly intervened in an area of central concern to Chinese elderly.

Mortuary Ritual. In a piece based on interviews with refugees and on secondary 
sources, Whyte (1988) explores the recent history and current status of death in China. He reviews the various government campaigns to limit expressions of mourning and to introduce cremation as the preferred alternative for disposing of the corpse. These proposals appear to have taken hold in the urban areas. In the rural areas, after a period of observing the ban on ostentatious displays and on having burial sites situated on arable land, these practices are beginning to return.

The changes in funerary rites which have occurred in urban areas appear to be significant. There the deceased is usually mourned in public rites conducted by the work unit which address the deceased's contribution to society. This contrasts to the traditional private rites which stressed the afterlife. As a consequence of the changed focus on positive contribution of the deceased, death is not seen as polluting nor are those associated with the death polluted, except in the case of a bad death like a suicide. Another significant change is the lack of sharp distinction made between mourners who are patrilineal kin and others or between sons and daughters.

Whyte (ibid) concludes that although the transformed urban funeral rites convey a different meaning, they continue to represent much of the traditional ideology e.g. the continuity between this world and the next, the responsibility of kin to find a proper resting place for the deceased's remains, and the influence on the living which the failure to attend to these matters can have.

\section{THE FUTURE OF GERONTOLOGICAL RESEARCH IN CHINA}

\section{Work in Progress}

The current research which is now being carried out in China, whose investigators have consented to provide descriptions for review, represents in-depth, theory-generated and analytical approaches to significant research problems. Roughly four kinds of questions are being addressed. The first is the impact on the elderly of the process of economic change, that is a re-examination of the "modernization" argument in light of the Chinese case. The second is an investigation of the role of a harsh environment on physical aging. The third is an examination of life cycle development in the context of significant social change. Finally, there is work that analyzes the dependency relationships involved in caregiving. The first three, especially the first one, explicitly focus on change, the fourth implicitly acknowledges it with the rapid growth in the elderly population used as a rationale for the study. With the exception of the study by Dong (1987), who attempted to develop a theoretical framework analyzing the relationship between state policies and family life and Davis (n.p.) who utilizes theories of meaning and context in her analysis of popular culture, these studies are rather more theoretical than those previously conducted. They promise to link the field of Chinese gerontology to major analytic and theoretical trends and to establish a solid basis for cross-cultural studies. 
An intensive ethnographic study of two villages in Zhejiang Province is being carried out by Melvyn Goldstein, Yachun $\mathrm{Ku}$ and Charlotte Ikels. The purpose of the project is to examine aging in a non-Western society undergoing the first stages of massive program of economic modernization. The theory guiding this undertaking is that the decrease in the status of the elderly which is commonly associated with the process of "modernization" is instead the outcome of specific conditions such as the elderly's loss of control over productive resources and/or the general level of poverty in a society which may force middle aged adults to allocate scarce resources to their children rather than their parents. Further, scarce economic conditions could encourage younger people to migrate out of an area and leave their elderly parents behind (Ikels, personal communication). They will examine the role of these specific factors as well as assess the role of traditional values such as filial piety in the fate of elderly rural Chinese under the responsibility system.

The research design will involve intensive participant-observation in two villages, one which has prospered under the new system and one which has not. As such it will be the first sustained ethnographic examination of the elderly in China. The design utilizes a kind of quasi-experimental approach in which participant-observation, interviews, historical record review, daily household activities and exchanges as well as survey data are combined to create two case studies which will then be compared to detect differences and to determine the factors which account for the differences in the status of the elderly in the different villages.

The design should allow the researchers to determine the manner in which economic and social changes affect access to and control over resources. Precise, in-depth data of this sort should help move the debate about the effects of modernization away from the examination of end results and toward a study of the process and forces which create those results. More specifically, village ethnographies conducted during this period will be extremely beneficial in documenting the extent to which the social welfare system which operated during the collectivization period has been dismantled and the effects this has had on the health and welfare of the elderly. Participant-observation will be particularly important not only for the processes and effects it will identify and document but also because it can elucidate the ways in which people's understanding of the social world and the events surrounding them affect family and community dynamics.

Melvyn Goldstein and Cynthia Beall, in collaboration with the Tibet Academy of Social Sciences in Lhasa, are conducting a project, a part of which examines how the dissolution of the communes has affected the elderly nomads in the Tibetan Autonomous Region. It will compare the status of the elderly during three periods, the traditional society (pre-1959), the early revolutionary period and the Cultural Revolution (1959-1981) and the post-Mao era of the new responsibility system (1981-1988). This study will also examine the physiological adaptation of the elderly to one of the harshest physical environments in the world. The completion of this study and the one by Goldstein, $\mathrm{Ku}$ 
and Ikels should allow this group of researchers to compare and contrast the Tibetan situation with that among the Han populations and to make a significant theoretical contribution to the debate concerning the status of the elderly in the modern world (Goldstein, personal communication).

Ikels is also involved in an intensive interview study designed to determine the impact of the needs of a rapidly aging population on society and on the family. (Preliminary results from this study were presented in the previous section.) She assessed the functional ability of the elderly using an assessment protocol of her own development, determined the expectations of the elderly and their family members as to patterns of care for the disabled elderly, and documented the types of care already being provided the disabled and infirm elderly. The interviews were carried out in two districts of urban Guangzhou. She utilized a random sampling design to select the neighborhoods and informants to be interviewed. One innovative and promising technique which Ikels employed was the presentation to the elder informant and at least one other adult family member of brief scenarios involving cultural and normative dilemmas. She then asked them, separately if possible, to comment on the dilemmas (personal communication). This research should produce not only valuable data on the contributions of healthy elderly to the household and the patterns of care for the disabled but also thick descriptive accounts of dilemmas posed in the care of disabled elderly. Comparing the intergenerational differences within the same family will be especially provocative. (See Ikels, 1988 for preliminary results.)

Yang Haiou is conducting sociological and demographic research on the effect of modernization on the well-being of rural elderly for her doctoral dissertation (personal communication). This study has four main objectives: (1) the predictions of the effect of demographic change in the last few decades on family size; (2) the exploration of the link between the well being of the elderly and family support and composition; (3) the examination of the effect of the new responsibility system on the family support network; and (4) the establishment of an empirical data base to be used in policy making for the elderly. She will use a microsimulation computer program to conduct family projections. During field research in rural villages in south China, she collected data for the quantitative and qualitative case study analysis.

A study on family change and the life course in Shanghai is being carried out by a group from the University of North Carolina, involving Glen Elder, Richard Udry, Gail Henderson and Anthony Obershall in collaboration with the Institute of Sociology at Shanghai University. This will be a survey research design involving random sampling to select a sample of 1200 respondents between the ages of 26-64. The study will utilize an event history methodology to be supplemented by a dozen "pop out" elaborations of important turning points in the life course such as first job, first marriage, migration, family formation, health crises, parents, sibs and children not in the respondent's household, sources of care for dependent household members, and societal events impact. It will also examine current household and family organization in such areas as 
family and household income transfers, division of labor, respondent's activities and chores, possessions, facilities and money management (Obershall, personal communication). By studying the elderly within the context of the family and the whole life course this approach is consonant with Chinese cultural notions of interdependence. Results from this research should enrich the study of crosscultural comparisons of life course development.

Studies directed at the family as a whole should help us understand better the context in which the elderly live and the forces which impinge on their well being and on the ability of their families to care for them. Janet Salaff and Burton Pasternak in collaboration with Pan Naigu and Ma Rong, from the Institute of Sociological Research, Beijing University, are conducting a study of families in three Han communities in Inner Mongolia. They will investigate the relationship between techno-economic setting and a number of sociological and demographic phenomena. During the first year a survey will be conducted of the three sites, to be followed by in-depth study of a sample of households and individuals in the next year. The project will address six general areas: (1) changes in technology and economy, (2) changes in domestic economy and their underlying causes, (3) changing patterns of marriage and postmarital residence, (4) changes in family form and composition as well as in the nature of intrafamilial relations, (5) demographic responses to policy innovations and to ecological and sociological diversity, and (6) patterns of, and factors affecting, migration (Salaff, personal communication).

\section{Analysis}

Gerontological studies in China are stimulating interest because of the opportunity they afford for significant cross-cultural comparisons, e.g. Goldstein, Ku and Ikels; Goldstein and Beall; Yang. So far the most effort has been in the area of "modernization". There are also important opportunities for exploring the relationship of the elderly and their status within society to Chinese society as a whole and to specific aspects of that society, e.g. Davis's work on age stratification (Davis-Friedmann, 1985a; Davis 1988). There are many other opportunities for gerontological research in China which address issues specific to that context and in addition may have cross-cultural implications. The following represent some examples of research questions which might be developed.

In a singular fashion for a lesser developed country, issues involving the elderly have come to the forefront of national policy development in response to the one-child family campaign. Studying the process of developing policies designed to reassure people that their old age will be secure even without many children to care for them, provides researchers with the opportunity to analyze the effect of state policy on family life in a profound fashion. Unlike many government policy initiatives which affect one phase of the life cycle but inadvertently touch other phases, the current policy initiatives explicitly acknowledge the link between old age care and birth control and thus are designed to have a more pervasive impact on the whole life cycle of individuals 
and families.

The question within this context is, of course, will such an ambitious policy actually have an impact on the family. The debate over the specific impact of state policy on family life is already underway. In their work Urban Life in Contemporary China Martin King Whyte and William L. Parish (1984) argue that the rise in age at marriage and sharp declines in fertility are not distinctively an outcome of state policies but rather represent the process of change in family patterns brought on by industrialization, urbanization, and the other forms of social change which are associated with modernity. The anthropologist, Arthur P. Wolf (1986), disagrees with the Whyte and Parish interpretation and argues that, although natural declines in fertility are inevitable and explain some of the decrease in fertility rates, the rapid pace of the decline could not have occurred without significant government intervention. In her thesis on family life in Shanghai (1987), Dong takes a different tack and contends that the relationship between government and family life is an interactive one and that, while the family responds to state policies in areas such as birth control, it can also act independently by voicing concerns through the work unit and make demands on the state forcing new policy initiatives in areas such as child care and housing.

The formation of policy concerning long term care for the elderly is just beginning. In contrast to earlier times, the state appears to be interested in promoting family harmony. According to some policy makers the idea is to "... redefine the family as 'the basic cell of society', the image of more complex social relations, capable of integrating, or of serving as a bridge between the individual and society" (China News Analysis, 1984). Studies which closely follow this development and people's perception of the policies and their response to them should contribute to an understanding of the intersection of individual family autonomy and state policies and to the place of the elderly in this system. Here Davis' (n.p.) work on household interiors may provide an example of exactly how ethnographic research can contribute to the attempt to achieve a more comprehensive understanding of the place and role of the family in society. Davis reports that, with one exception, there was no evidence of political or work related themes in her informants' homes. This points to the clear primacy of the familial in people's lives, and of the inability of the state to control the content of popular culture. Ethnographic studies of this type are needed to understand the effect of state policy on the elderly within the family.

In line with an examination of the relationship between state policy and the family in the area of long term care, documentation of the singular cultural role played by the elderly in political life is significant. Davis-Friedmann (1983) describes how the elderly were utilized during political campaigns as witnesses attesting to the horrible life before the revolution and the substantial improvements following it. Under the Cultural Revolution, however, the elderly sometimes suffered as representatives of the old order (Olsen, 1988). Currently the elderly are promoted as models of traditional values and as teachers of moral obligations and discipline to their married children of child-bearing age (China News Analysis, 1984). It would be intriguing to explore how this unique 
political role for the elderly has affected their perception of personal and social generativity.

The impact of economic and social change on the extended family will be an important area of concern in developing an understanding of the status and well being of the elderly. This is closely related to the above topics but distinct in that it focuses on intergenerational relations directly and other larger forces only indirectly. Based on research conducted in China, Croll (1987) describes an emerging family organization which she calls the "aggregate family" refering to separate nuclear units which continue to cooperate economically. Croll argues that the elaboration and strengthening of family networks is an advantage to the peasant family under the new responsibility system. This "aggregate" organization provides its members with access to capital for investments, labor exchange, employment, and urban ties. At the same time, she notes, the number of nuclear households has risen while the number of multi-generational, stem, and joint households has declined. If this is in fact a trend, it is not clear what the implications for the elderly will be. Perhaps they will live in separate residences but participate in an economically more efficient and interdependent family. Possibly in the short run, prior to adequate capital production, this could be detrimental to the elders. The situation could change for the better once sufficient surpluses are being generated.

The intense family focus does not bode well for those single and childless elderly who were dependent on the communal social welfare system. One suggestive development, which is not clearly related to the well being of the elderly but may affect them, is the desire of the successful peasant families to not call attention to themselves. Croll reports that rich households, to forestall criticism from neighbors and potentially the state if economic policies should change, are making an effort to integrate less fortunate kinsmen into successful enterprises. Possibly some social welfare benefit will arise from the same motivation. Village level as well as urban ethnographies will be important here in understanding family change and the impact this will have on the elderly.

Finally there is a clear need for more studies on such classic topics of ethnographic interest as mortuary ritual and ancestor worship. We know from the work of Davis-Friedmann (1983), Huang (forthcoming) and Parish and Whyte (1977) and Whyte (1988) that traditional funerals and ancestor worship are still practiced in some form, especially in the countryside, despite the prohibitions of the collectivization period. In what form these practices will continue and what effect smaller family size will have on them will be important questions for anthropologists as well as for the elderly themselves.

\section{Conclusion}

Ethnography has an important contribution to make to the rapidly expanding field of Chinese gerontology. The large scale surveys which are currently being conducted or are in the planning stages will need ethnographic input both to ensure that the interview questions are culturally meaningful and to identify the 
specific cultural and social context of the respondents so as to determine their relevance for the population at large. Ethnographic studies will be important in their own right. Extended participant-observation studies are needed to document the process and impact of social and economic change. Repeated longitudinal studies in the same village or urban district would be especially beneficial. Studies on purely ethnographic topics which document cultural practices, meanings and beliefs are needed.

State policy in China has had a profound impact on the position and role of the elderly and their experience of their lives. This has been accomplished through demographic policy, employment policy, and policies aimed at changing social and cultural life, in particular mortuary practices and ancestor worship but also patrilineality. The effect of these policies is still being determined and in fact remains in flux as the new responsibility system stimulates still more change in the social and economic structure of society. Although these changes affect everyone's life, analyzing them from the perspective of the elderly is particularly insightful because they appear to challenge a central Chinese cultural value - that of filial piety. Studying the elderly will thus provide a window into the larger question of what constitutes Chinese cultural identity in modern China.

\section{NOTES}

1 The author wishes to thank the following colleagues for helping to identify researchers working in this area, Deborah Davis, Charlotte Ikels, Victor Nee, Martin King Whyte.

2 The author attempted to make this review as inclusive as possible. If any researcher's work was omitted, it was done so unintentionally.

3 The author wishes to acknowledge the extremely beneficial criticisms of the outside reviewers. Their contributions considerably improved the quality of this piece.

\section{BIBLIOGRAPHY}

\section{English Sources}

Baker, H. 1968 A Chinese Lineage Village: Sheung Shui. Stanford: Stanford Univ. Press. Bannister, J. 1987 Implications of the aging of China's population. Presented at the International Symposium on Family Structure and Population Aging, Beijing, China, October, 1987.

Barclay, G. W. 1954 Colonial Development and Population in Taiwan. Princeton: Princeton University Press.

Cain, M. 1985 Fertility as an adjustment to risk. In Rossi, A. Gender and the Life Course New York: Aldine, 145-161.

China News Analysis 1984 Socialist China, social policy and the elderly. 1257, March 26.

China News Analysis 1987 Working women. 1334, May, 1.

China Population Research 1987 2(1).

Cohen, M. 1976 House United, House Divided. New York: Columbia. 
Croll, E. 1987 The Aggregate Family: Households and Kin Support in Rural China. Delivered at the International Symposium on Family Structure and Population Aging. October 21-25, 1987. Beijing, China

Davis, D. 1986 Family Supports for Chinese elderly: current and future trends. Delivered at the Annual Meetings of the Gerontological Society of America, Chicago, III.

Davis, D. (1988) Unequal choices; unequal lives: pension reform and urban inequality. China Quarterly 114:223-242.

Davis, D. My mother's house. in New Ways of Studying Popular Culture in China. edit. R. Madsen and L. Pikowitcz. Westview.

Davis-Friedmann, D. 1983 Long Lives: Chinese Elderly and the Communist Revolution. Cambridge: Hardvard University Press.

Davis-Friedmann, D. 1985a Intergenerational inequalities and the Chinese revolution. Modern China 11(2):177-201.

Davis-Friedmann, D. $1985 \mathrm{~b}$ Old age security and the one-child campaign. In Croll, E., Davin, D. and Kane, P. eds. China's One-Child Family Policy London: MacMillan.

Diamond, N. $1969 K^{\prime}$ un Shen: A Taiwanese Village. New York: Holt, Reinhart and Winston.

Dong, B. 1987 Contemporary Chinese Intellectual Families. A doctoral dissertation, University of California-Santa Barbara.

Fei, H. 1949 Earthbound China. London: Routledge \& K. Paul.

Freedman, M. 1958 Lineage Organization in Southeastern China. London School of Economics Monographs on Social Anthropology, 18. London: Athlone.

Freedman, M. 1966 Chinese Lineage and Society: Fukien and Kwangtung. London School of Economics Monographs on Social Anthropology, 33 London: Athlone.

Fried, M. 1953 Fabric of Chinese Society. New Haven: Yale University Press.

Gallin, B. 1966 Hsin Hsing, Taiwan: A Chinese Village in Change. Berkely and Los Angeles: University of Califomia Press.

Gamble, S. 1954 Ting Hsien: A North China Rural Community. New York: Institute of Pacific Relations.

Greenhalgh, S. 1986 Shifts in China's population policy, 1984-86: Views from the central, provincial, and local levels, Population and Development Review 12(3):491-512.

Greenhalgh, S. 1988 Population research in China: an introduction and guide to institutes. Center for Policy Studies Working Papers The Population Council, no. 137.

Greenhalgh, S. and John Bongaarts 1987 Fertility policy in China: future options. Science 235:1167-1172.

Gui, S. X., Ki, L. K., Shen, Z. N., Di, J. X., Gu, Q. Z., Chen, Y. M., Qian, F. 1987 Status and needs of the elderly in urban Shanghai: analysis of some preliminary statistics. Journal of Cross-Cultural Gerontology 2:171-186.

Ho, P. 1962 The Ladder of Success in Imperial China. New York: Science Editions.

Hsu, F. 1948 Under the Ancestors Shadow: Chinese Culture and Personality. Stanford: Stanford University Press.

Hu, R., Wang, L., Zhang, Y. 1987 The roles of Chinese urban elderly in social development: direct and indirect participation. In Aging in China: Family, Economics and Government Policies in Transition. Wash DC: Gerontological Society of America.

Huang, Shu-min (n.p.) The Spiral Road: Changes and Development of a Chinese Village through the Eyes of a Communist Party Cadre.

Ikels, C. 1983 Aging and Adaptation: Chinese in Hong Kong and the United States. Hamden, Ct: Archon.

Ikels, C. 1988 New Options for Chinese Elders. Delivered at a conference on Social Consequences of the Chinese Economic Reforms, Harvard University, May 13-15 1988.

Ikels, C. Forthcoming. Family caregivers and the elderly in China. In Aging and Caregiving: Theory, Research and Practice. Eds. D. Biegel and A. Blum. Newbury 
Park, CA: Sage.

Keyfitz, N. 1984 The population of China. Scientific American 250: 38-47.

Kleinman, A. 1980 Patients and Healers in the Context of Culture. Berkeley: University of California Press.

Lang, O. 1946 Chinese Family and Society. New Haven: Archon.

Liang, J., Tu, E.J.-C., Chen, X. 1985 Population aging in People's Republic of China. Delivered at the Population Association of America, Boston Mass. March 28-30, 1985.

Liang, J., Gu, S. (n.p.) Long term care in China.

Lin, Y. 1948 The Golden Wing: A Sociological Study of Chinese Familism. New York.

Liu, W. T. and Yu. E. 1988 Informal social support systems for the elderly in Shanghai, China. Delivered at the Annual Gerontological Society of America Meetings San Francisco, November, 1988.

Nee, V., Wong, H. Y. 1985 Asian American socioeconomic achievement: the strength of the family bond. Sociological Perspectives 28(3): 281-306.

Nee, V., Wong, H. Y. 1986 The peasant household economy and decollectivization in China. Journal of Asian and African Studies 21(3-4): 185-203.

Olsen, P. 1987 A model of eldercare in the People's Republic of China. International Journal of Aging and Human Development 24: 279-300.

Olsen, P. 1988 Modernization in the People's Republic of China: the politicization of the elderly. The Sociological Quarterly 29(2): 241-262.

Parish, W. L. and Whyte, M. K. 1977 Village and Family in Contemporary China. Chicago: University of Chicago Press.

Pasternak, B. 1968 Atrophy of patrilineal bonds in a Chinese village in historical perspective. Ethnohistory 15:3 (Summer).

Pasternak, B. 1986 Marriage and Fertility in Tianjin, China: Fifty Years of Transition. Paper of the East-West Population Institute, Number 99 July, Honolulu: East West Center.

Sankar, A. 1981 The conquest of solitude: singlehood and old age in traditional Chinese society. In Fry, C. Dimensions: Aging, Culture, and Health South Hadley: Bergin, $65-85$.

Sankar, A. 1978 The evolution of the sisterhood in traditional Chinese society: from village girls' houses to chai t'angs in Hong Kong unpublished $\mathrm{PhD}$ dissertation Ann Arbor: University of Michigan.

Schultz, J., Davis-Friedmann, D. 1987 Aging China: Family, Economics, and Government Policies in Transition. Proceeds of the International Forum on Aging, Beijing, China May 20-23, 1986 Wash DC: Gerontological Society of America.

Tawny, R. 1932 Land and Labour in China. London: Beacon.

Treas, J., Logue, B. 1986 Economic development and the older population. Population and Development Review 12(4): 645-673.

Tu, E. J.-C., Liang, J., Li, S. 1987 Mortality decline and Chinese family structure: implications for old age support. Revised version of paper delivered at Annual Meeting of Population Association of America, April 30-May 2, Chicago, $\mathrm{Il}$.

Whyte, M. K. 1988 Death in the People's Republic of China. In Death Ritual in Late Imperial and Modern China eds. J. L. Watson and E. S. Rawski, Berkeley: University of California Press.

Whyte, M. K. and Parish, W. L. 1984 Urban Life in Contemporary China. Chicago: University of Chicago Press.

Wolf, A. 1986 The preeminent role of government in intervention in China's family revolution. Population and Development Review 12(1): 101-117.

Wolf, A. 1968 Adopt a daughter-in-law, marry a sister: a Chinese solution to the problem of the incest taboo. American Anthropologist 70 no. 5.

Wolf, M. 1972 Women and the Family in Rural Taiwan. Stanford: Stanford University Press. 
Yang, C. K. 1959 The Chinese Family in the Communist Revolution. Cambridge, Mass.: Harvard Press.

Yang, M. 1945. A Chinese Village: Taitou, Shangtung Province London: K. Paul, Trench Trubner.

Yu, E., Liu, W. T., Levy, P., Zhang. M. Y., Katzman, R., Lung, C. T., Wong, S. C., Wang, Z. Y., Qu, G. Y. forthcoming Cognitive impairment among the elderly in Shanghai, China. Journal of Gerontology: Social Sciences.

Yuan, F. 1987 The status and role of the Chinese elderly in families and society. In Aging China: Family, Economics, and Government Policies in Transition eds. Schultz, J. and Davis-Friedmann, D. Proceeds of the International Forum on Aging Beijing, China May 20-23, 1986, Wash. DC: Gerontological Socicty of America.

\section{Chinese Sources}

Xia Lianbo 1978 Laonian Baojian Zhishi (Information for Preserving the Health of the Old). Shanghai: Kexue Jishu Chubanshe.

Yuan Jihui 1986 (ed.) Laonian Wenti (Problems of Old Age). Shanghai: Fudan Daxue Chubanshe.

Yuan Jihui (ed.) Chengshi Laonian Shenghuo Yamjiu (Research on Urban Elderly). Shanghai: Shanghai Laonianren Wenti Group, Volume I and II.

Dept. of Anthropology

University of Michigan

Ann Arbor, MI 48109-1382 